\title{
Correction to: A panorama of radial nerve pathologies- an imaging diagnosis: a step ahead
}

Aakanksha Agarwal ${ }^{1{ }^{*}}$, Abhishek Chandra $^{2+}$, Usha Jaipal ${ }^{1}$ and Narender Saini ${ }^{2}$

\section{Correction to: Insights Imaging}

$$
\text { https://doi.org/10.1007/s13244-018-0662-x }
$$

The original article [1] contains an omission in authorship detail; authors Aakanksha Agarwal and Abhishek Chandra are instead joint first authors.

\section{Author details}

${ }^{1}$ Department of Radiodiagnosis and Modern Imaging, SMS Medical College and Attached Hospitals, Jaipur, Rajasthan, India. ${ }^{2}$ Department of

Orthopaedics, SMS Medical College and Attached Hospitals, Jaipur, Rajasthan, India.

Received: 24 January 2019 Accepted: 24 January 2019

Published online: 06 February 2019

\section{Reference}

1. Agarwal A, Chandra A, Jaipal U, Saini N (2018) A panorama of radial nerve pathologies- an imaging diagnosis: a step ahead. Insights Imaging 9:6

\footnotetext{
* Correspondence: a.agarwal.1992@gmail.com

The original article can be found online at https://doi.org/10.1007/s13244018-0662-x

${ }^{\dagger}$ Aakanksha Agarwal and Abhishek Chandra contributed equally to this work.

${ }^{1}$ Department of Radiodiagnosis and Modern Imaging, SMS Medical College and Attached Hospitals, Jaipur, Rajasthan, India

Full list of author information is available at the end of the article
} 